\title{
Synthesis and Performance of Functionalized $\alpha$-Zirconium Phosphate Modified with Octadecyl Isocyanate
}

\author{
Lijuan Han, ${ }^{1,2}$ Qingyuan Chen, ${ }^{2}$ Hong Chen $\mathbb{D}^{1},{ }^{1}$ Shang $Y u,{ }^{1}$ Lin Xiao $\mathbb{D},{ }^{1}$ and Zhongbin Ye ${ }^{1,2}$ \\ ${ }^{1}$ State Key Laboratory of Oil and Gas Reservoir Geology and Exploitation, Southwest Petroleum University, Chengdu 610500, China \\ ${ }^{2}$ School of Chemistry and Chemical Engineering, Southwest Petroleum University, Chengdu 610500, China \\ Correspondence should be addressed to Hong Chen; chenhong_919@163.com
}

Received 23 November 2017; Revised 26 January 2018; Accepted 27 May 2018; Published 24 June 2018

Academic Editor: Yong Ding

Copyright (c) 2018 Lijuan Han et al. This is an open access article distributed under the Creative Commons Attribution License, which permits unrestricted use, distribution, and reproduction in any medium, provided the original work is properly cited.

\begin{abstract}
The $\alpha$-zirconium phosphate ( $\alpha$-ZrP) and hydrophobically modified $\alpha$-zirconium phosphate $(\alpha$-ZrP-I) were prepared. The grafting of octadecyl isocyanate was confirmed by Fourier transform infrared (FTIR) spectra, X-ray diffraction (XRD), and thermogravimetric analysis (TGA). The dispersion of $\alpha$-ZrP-I was studied by environmental scanning electron microscopy (SEM). The wettability of $\alpha$-ZrP-I was determined by Kruss DSA30. Then, the effects of decompression and augmented injection of $\alpha$-ZrP-I have been studied. The results of water flooding experiments show that the appropriate concentration of $\alpha$-ZrP-I has an effect on the decrease of the water injection pressure.
\end{abstract}

\section{Introduction}

The $\alpha$-zirconium phosphate, $\alpha$ - $\mathrm{ZrP}\left(\mathrm{HPO}_{4}\right)_{2} \cdot \mathrm{H}_{2} \mathrm{O}$, with its layer spacing of $0.76 \mathrm{~nm}$, is a structured cationic layered compound with a monoclinic system. Its crystal structure is the lamellar composed of octahedral $\mathrm{ZrO}_{6}$ and tetrahedral $\mathrm{HPO}_{4}$ alternately. Due to the molecular structure of $\alpha$-zirconium phosphate, it is possible for $\alpha$-ZrP and its derivatives to become excellent matrix of intercalated compounds, pillared catalysts and polymers, and layered inorganic nanocomposites. And these materials have broad applications in ion exchange, adsorption catalysis, electromagnetics, electrochemistry, photochemistry, biomedicine, environmental protection, and other fields [1-16]. There are three main methods for the preparation of $\alpha$-zirconium phosphate: reflux method, direct precipitation method (fluorine coordination method), and hydrothermal method [17-20]. Among these methods, the reflux method is widely used because of its great potential for large-scale synthesis. The particle size of $\alpha$-zirconium phosphate prepared by the reflux method is tiny, and colloidal particles are easy to acquire, which is beneficial to the subsequent modification process of $\alpha$-zirconium phosphate.

As a typical layered compound, the layer spacing of $\alpha$-zirconium phosphate can be designed and it exhibits anisotropy. The $\alpha-\mathrm{ZrP}$ has good chemical activity, such as reduction reaction, polymerization, replacement reaction, stripping layer reaction, and other reactions [21-34]. Owing to the excellent properties of $\alpha$-zirconium phosphate, domestic and foreign scholars have done a series of studies about $\alpha$-ZrP. Intergranular protons in the $\alpha$-ZrP have strong ion exchange capacity; different guest molecules can be inserted into the $\alpha$-ZrP layer for intercalation. MacLachlan studied the insertion of alkylamine into $\alpha$-ZrP [32]; he thought that the arrangement of different alkylamines is related to the amount of intercalation. The short chain alkylamine with a variety of permutations not only increases the alkylamine layer spacing, but also introduces hydrophobic groups, making intercalated compounds strong hydrophobicity. For some organic molecules that could not be directly inserted into $\alpha-\mathrm{ZrP}$, they can be intercalated by alkylamine and then introduced into the interlayer with alkylamine. 


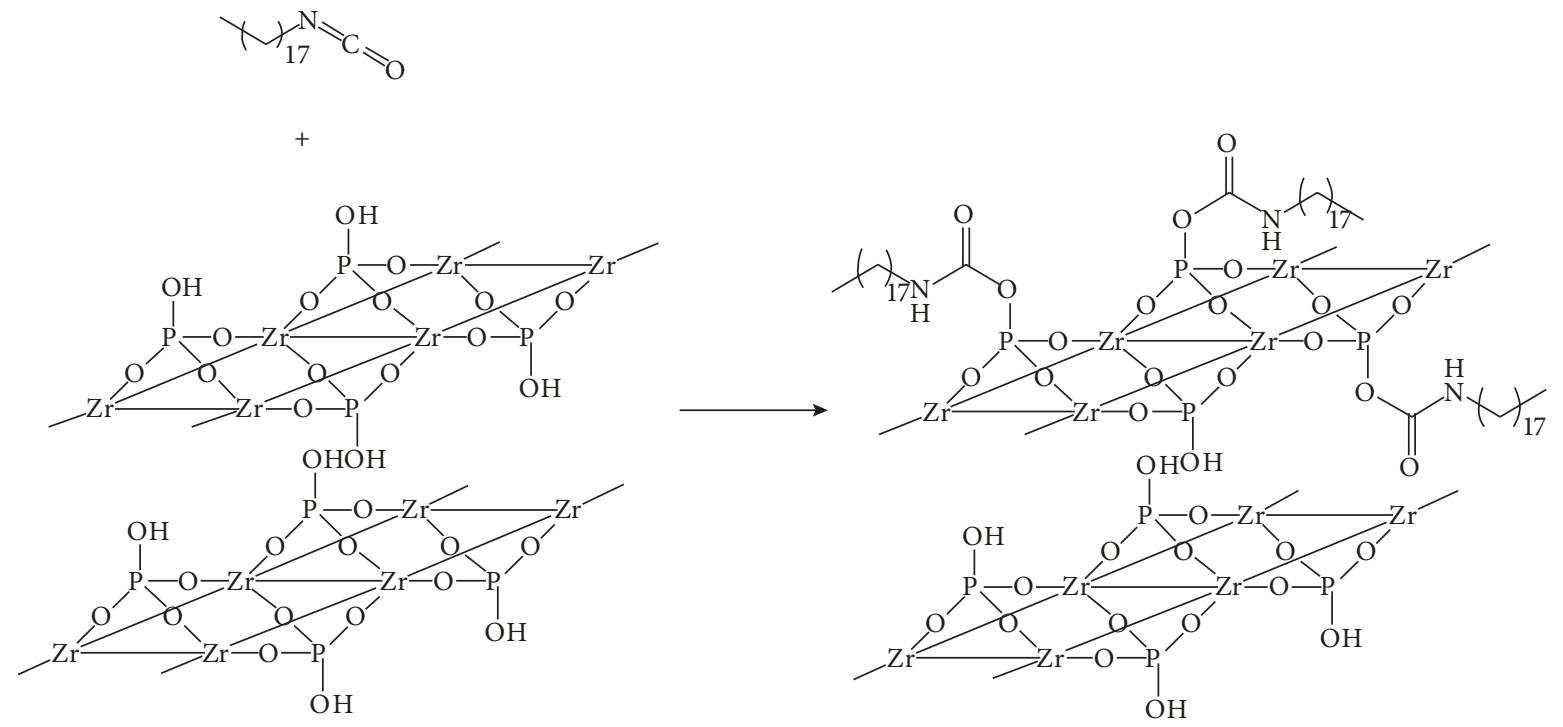

FIGURE 1: Scheme of hydrophobic modification of $\alpha$-zirconium phosphate.

Octadecyltrichlorosilane could be grafted onto the surface of $\alpha$ - $\mathrm{ZrP}$ through the $\mathrm{P}-\mathrm{OH}$ group reaction. The surface of $\alpha$-ZrP modified by hydrophobic long chains will exhibit strong hydrophobicity. The application of modified $\alpha$-ZrP products in photo-induced electron transfer reactions in nonpolar solvents also has been studied.

With the development of oil and gas exploitation, many middle- and high-permeability reservoirs have been in medium or high water level development stage. As a result, the low-permeability reservoirs will be the major resource. But the development of low-permeability reservoirs was limited by their poor properties and poor injection production connectivity, which rapidly increases water injection pressure and dramatically decreases water intake capacity during the water flooding process. In order to reduce water injection pressure and increase water injection volume, the flow resistance during water flooding should be reduced.

The strong hydrophobic nanomaterials have the ability to make the surface wettability of the rock formation transform from hydrophilicity to hydrophobicity and then the subsequent injected water flows on the nanoadsorption layer. The contact angles of the core with water before and after the treatment by the nanomaterials could confirm the change of the wettability of the core surface. In accordance with the mechanism of nanoslippage effect, it is considered that the nanomaterials have strong surface activity, and they perform competition adsorption with water molecules on the wall of the micropore. Nanomaterials will replace the original hydration layer to form a molecular adsorption layer with superhydrophobic properties and nanoscale $[35,36]$. When the water flows through the adsorption layer, the nanoslippage effect generates, which helps to expand the effective pore size and reduce flow resistance.

Hydrophobic $\alpha$-ZrP nanomaterial may exhibit a significant effect on decompression and augmented injection and can be used for low-permeability reservoir water flooding development. In this paper, $\alpha$-ZrP was prepared by the reflux method, and then the $\alpha$-ZrP was modified by octadecyl isocyanate to obtain the hydrophobically modified product $\alpha$-ZrP-I. The performance of $\alpha$-ZrP-I as a drag reducer was evaluated. The experiment results show that $\alpha$-ZrP-I has good performance in drag reduction, which has potential applications in low-permeability reservoirs.

\section{Materials and Method}

2.1. Materials. Zirconium oxychloride, concentrated phosphoric acid, octadecyl isocyanate, o-xylene, tetrahydrofuran, and methanol were purchased from Chengdu Kelong Chemical Reagent Company, China.

2.2. Preparation of $\alpha-Z r P$ and $\alpha-Z r P-I$. The $\alpha-Z r P$ was prepared by the reflux method. The concentrated phosphoric acid was first diluted to $11 \mathrm{~mol} \mathrm{l}^{-1}$. Then, $3.22 \mathrm{~g}$ Zirconium oxychloride $\mathrm{ZrOCl}_{2} \cdot 8 \mathrm{H}_{2} \mathrm{O}$ was dissolved in deionized water and slowly dropped into the continuously stirred phosphoric acid solution which was about $40 \mathrm{ml}$. The mixture system would be refluxed under $100^{\circ} \mathrm{C}$ for 24 hours. Finally, the product would be filtered and washed repeatedly with deionized water several times to remove unreacted phosphoric acid and other impurities until the $\mathrm{pH}$ of the filtrate was neutral. The product was placed in a vacuum oven at $60^{\circ} \mathrm{C}$ for about 12 hours and then grinded into white powder.

Then, $1.416 \mathrm{~g} \alpha$-ZrP was dispersed into $50 \mathrm{ml} \mathrm{o-xylene}$ in a three-necked flask and ultrasonically dispersed for 2 hours (ultrasonic power was set at $100 \mathrm{~W}$ ). $0.150 \mathrm{~g}$ octadecyl isocyanate was added into the $\alpha$-ZrP dispersed system (the molar ratio of $\mathrm{ZrP}$ to ODI is $10: 1$.) and reacted for 12 hours under the condition of nitrogen gas. Then, the mixture was centrifuged and the product was washed with methanol several times to remove impurities. The product was dried in an oven at $60^{\circ} \mathrm{C}$ to obtain the hydrophobically modified $\alpha$-zirconium phosphate $(\alpha$-ZrP-I) solid powder. The reaction scheme is shown in Figure 1. 


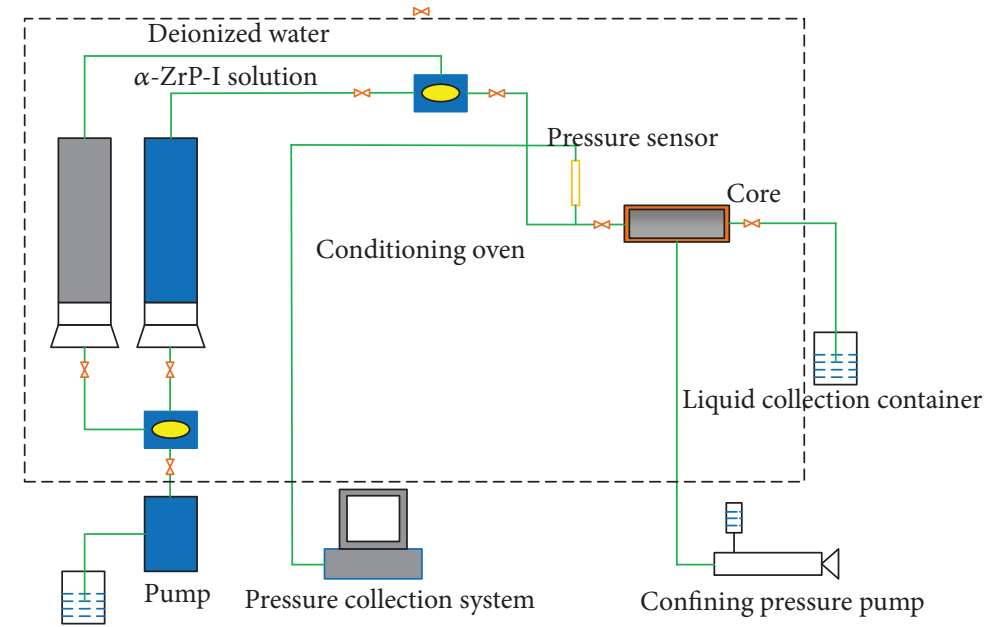

FIGURE 2: Schematic diagram of $\alpha$-ZrP-I flooding experiment.

2.3. Characterization. The Fourier transform infrared (FTIR) spectra of $\alpha$-ZrP and $\alpha-\mathrm{ZrP}$-I were recorded by Thermo Fisher Scientific Nicolet 6700 ranging from 800 to $4000 \mathrm{~cm}^{-1}$. X-ray diffraction (XRD) measurements were performed directly on the powder sample of $\alpha-\mathrm{ZrP}$ and $\alpha-\mathrm{ZrP}-\mathrm{I}$ by using PANalytical X'Pert-Pro diffractometer $(40 \mathrm{kV}, 40 \mathrm{~mA})$ with $\mathrm{Cu}(\lambda=1.54 \AA)$ irradiation at a scanning of $2 \%$ in the $2 \theta$ range of $4 \sim 40^{\circ}$, and scan compensation is $20^{\circ} / \mathrm{min}$. Thermogravimetric analysis (TGA) was carried out with a NETZSCH simultaneous thermal analyzer model STA 449F3. The heating rate was $10^{\circ} \mathrm{C} / \mathrm{min}$. Each time about $10 \mathrm{mg}$ sample was measured in an aluminum crucible under inert gas atmosphere from $40^{\circ} \mathrm{C}$ to $800^{\circ} \mathrm{C}$. Scanning electron microcopy (SEM) measurements were implemented by a field emission scanning electron microanalyzer (FEI Quanta 450) at an accelerating voltage of $20 \mathrm{kV}$. Contact angle was determined by Kruss drop shape analyzer model DSA30.

2.4. Evaluation of Core Flooding Experiment. All the displacement experiments were conducted through multifunctional chemical flooding physical simulation system (Haian Oil Scientific Research Apparatus Co. Ltd.). Schematic diagram of experiment is shown in Figure 2. The pressure during the injection process was recorded. The injection rate was $0.5 \mathrm{ml} / \mathrm{min}$. The detailed process is as follows:

(1) Put the core into the core holder and inject deionized water in the core to determine the initial water-phase permeability of the core.

(2) Displace the cores with simulated oil.

(3) Displace the cores with deionized water again to set residual oil saturation and obtain the stable water flooding pressure $P_{1}$.

(4) Inject $\alpha$-ZrP-I dispersion system, close the valve of the holder, and put it aside for 24 hours.

(5) Do subsequent water flooding injection to obtain the stable water flooding pressure $P_{2}$.

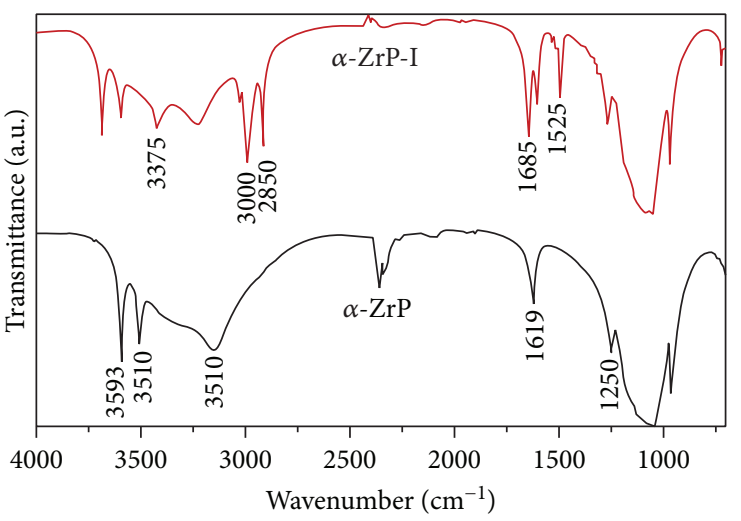

Figure 3: FTIR spectra of $\alpha$-ZrP and $\alpha$-ZrP-I.

According to the core flow experiment method, the effect of $\alpha$-ZrP-I on the development of water injection in the lowpermeability core was evaluated through comparing the pressure before and after the injection of nanomaterial.

\section{Results and Discussion}

The particle size of $\alpha$-zirconium phosphate is between $100 \mathrm{~nm}$ and $400 \mathrm{~nm}$ with $0.76 \mathrm{~nm}$ interlayer distance. The $\alpha$-ZrP has good chemical activity, so it is possible to graft the organic group onto the surface of the $\alpha$-zirconium phosphate crystal for the transformation of the nature of the original nanometer lamellae.

In this paper, octadecyl isocyanate was utilized to modify the surface of $\alpha$-zirconium phosphate to prepare hydrophobically modified $\alpha$-zirconium phosphate. The octadecyl isocyanate was grafted onto the surface and the edge of the $\alpha$-zirconium phosphate sheet by chemical reaction with the $-\mathrm{OH}$ group on the surface.

3.1. Fourier Transform Infrared (FTIR) Spectroscopy. FTIR spectra of the original $\alpha-\mathrm{ZrP}$ and hydrophobically modified $\alpha$-ZrP-I are presented in Figure 3. For the $\alpha$-ZrP spectrum, 


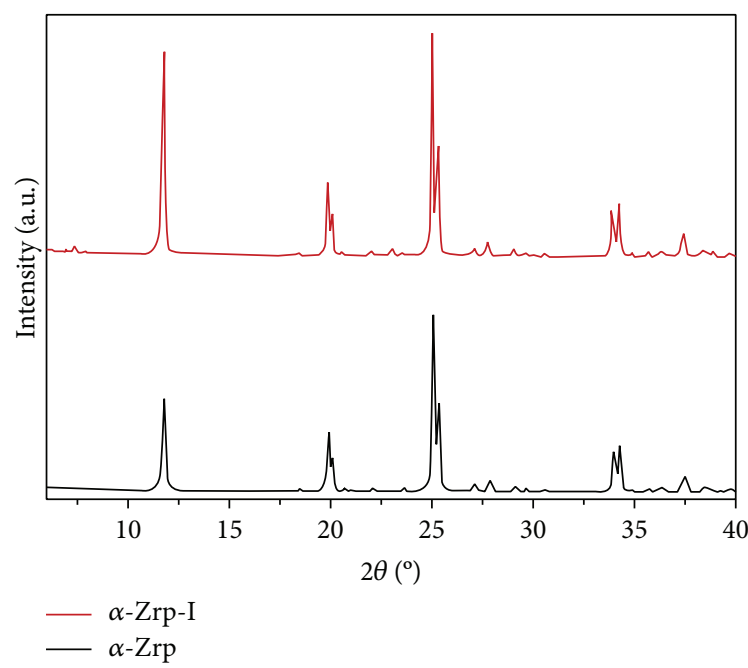

Figure 4: XRD patterns of $\alpha$-ZrP and $\alpha$-ZrP-I.

there are two distinct peaks at $3590 \mathrm{~cm}^{-1}$ and $3510 \mathrm{~cm}^{-1}$, which are the asymmetric stretching vibration of the intercalated water molecules, due to the split of the position asymmetry. The characteristic peak at $3150 \mathrm{~cm}^{-1}$ is symmetric stretching vibration absorption peak of the intercalated water molecules, and the characteristic peak at $1620 \mathrm{~cm}^{-1}$ is the absorption peak caused by the deformation vibrations of the $\mathrm{O}-\mathrm{H}$ bonds of the water molecules. The peak at $1250 \mathrm{~cm}^{-1}$ belongs to the out-of-plane bending vibration of $\mathrm{P}-\mathrm{OH}$. The strong absorption peak at $1000 \sim 1200 \mathrm{~cm}^{-1}$ is the stretching vibration peak of $-\mathrm{PO}_{4}$ group. The IR spectra of prepared $\alpha-\mathrm{ZrP}$ are consistent with the standard $\alpha-\mathrm{ZrP}$ IR spectra.

For the $\alpha$-ZrP-I spectra, the characteristic peak emerging at $3375 \mathrm{~cm}^{-1}$ is the absorption peak of secondary amine. The strong characteristic peaks which emerge near 3000$2850 \mathrm{~cm}^{-1}$ are symmetrical and asymmetric stretching vibration peaks of methylene. Two carbonyl characteristic absorption peaks are observed, one of which is carbonyl characteristic absorption peak of aliphatic carboxyl group at $1685 \mathrm{~cm}^{-1}$, and the other one of which is carbonyl characteristic absorption peak of amide group at $1525 \mathrm{~cm}^{-1}$. Compared with the $\alpha$-ZrP infrared spectra, these newly emerged peaks indicate that the octadecyl isocyanate molecules are successfully attached to the $\alpha$-ZrP crystal surface. The characteristic absorption peaks of the original interlayer water molecules still exist, indicating that the intercalation reaction does not occur during the modification process. The octadecyl isocyanate does not insert into the $\alpha$-ZrP crystal layer which still maintains a stable layered structure, and it only modifies the surface and the edge of the crystal.

3.2. X-Ray Diffraction (XRD). The XRD patterns of $\alpha$ - ZrP and $\alpha$-ZrP-I are shown in Figure 4 . The results of spectra analysis of $\alpha$-ZrP-I remain the same as that of $\alpha$ - ZrP without obvious difference. There are three main strong diffraction peaks at $11.6^{\circ}, 19.7^{\circ}$, and $24.9^{\circ}$, corresponding to the characteristic diffraction peaks of $\mathrm{d}$ (002), $\mathrm{d}$ (110), and $\mathrm{d}$ (112),

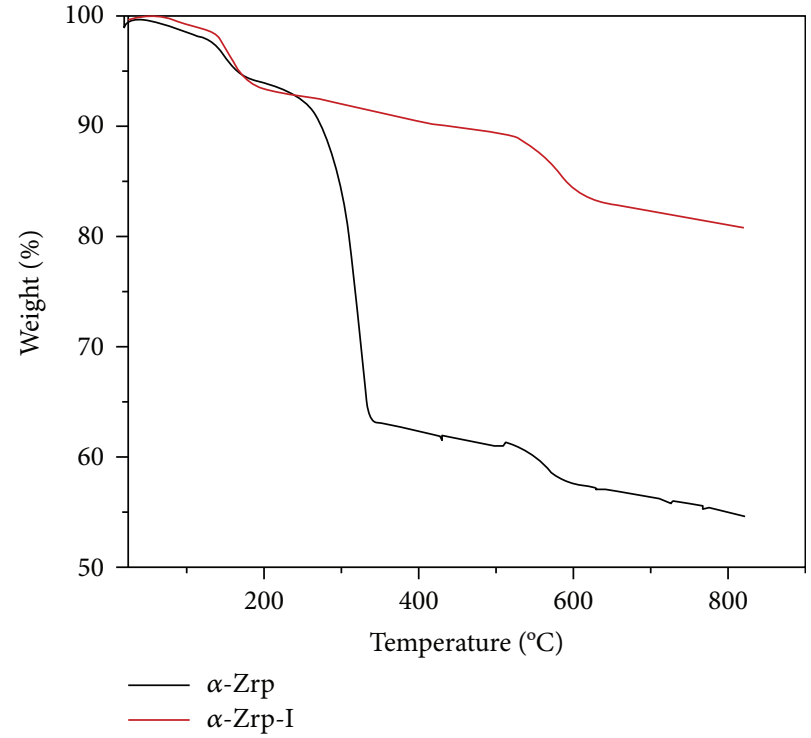

FIgure 5: TGA curves of $\alpha$-ZrP and $\alpha$-ZrP-I.

respectively. The first characteristic peak represents the 002 crystal plane of $\alpha-\mathrm{ZrP}$ with its interlayer spacing of $0.76 \mathrm{~nm}$, which indicates that the layer interval of $\alpha$-ZrP keeps unchanged after hydrophobic modification, that is, the octadecyl isocyanate does not insert into crystal layer of $\alpha-\mathrm{ZrP}$ during surface modification process.

3.3. Thermogravimetric Analysis (TGA). Figure 5 shows the TGA curves of $\alpha$-ZrP and $\alpha$-ZrP-I. Below $200^{\circ} \mathrm{C}, \alpha$-ZrP exhibits a weight loss of about $6 \%$; it is attributed to the loss of the first level of interlayer crystallization water and the production of $\alpha-\mathrm{Zr}\left(\mathrm{HPO}_{4}\right)_{2}$. The $\alpha$ - ZrP begins to ongoing condensation reaction at about $500^{\circ} \mathrm{C}$. There is the same mass loss in second-level process at $500^{\circ} \mathrm{C} \sim 600^{\circ} \mathrm{C}$, which is caused by the dehydration condensation reaction of $\mathrm{P}-\mathrm{OH}$ of $\alpha-\mathrm{Zr}\left(\mathrm{HPO}_{4}\right)_{2}$ layer structure which generates $\mathrm{ZrP}_{2} \mathrm{O}_{7}$. The decomposition temperature is relatively high, indicating that $\alpha$-ZrP could well maintain the layered structure and has good thermal stability.

The TGA curve of $\alpha$-ZrP-I basically appears four stages. The first stage ranges from $40^{\circ} \mathrm{C}$ to $100^{\circ} \mathrm{C}$, which the residual adsorbed solvent molecules on the prepared $\alpha$-ZrP-I surface are heated and volatilized. The second temperature stage is within $100^{\circ} \mathrm{C}$ to $200^{\circ} \mathrm{C}$, which the interlayer crystal water molecules are removed for heated and the weight loss is about $6 \%$. This is consistent with the result of TGA of $\alpha-\mathrm{ZrP}$ at $200^{\circ} \mathrm{C}$. The temperature range from $200^{\circ} \mathrm{C}$ to $330^{\circ} \mathrm{C}$ signifies the third stage. The weight loss of the modified product $\alpha$-ZrP-I in this stage is greater than the two stages mentioned above, as the organic aliphatic hydrocarbon chain on the surface begins to be decomposed when heated. Organic long-chain alkyl falls off from $\alpha$-ZrP surface until the organic modifier has been fully decomposed at around $350^{\circ} \mathrm{C}$. The last weight loss stage of $\alpha$-ZrP-I is within the range from $505^{\circ} \mathrm{C}$ to $600^{\circ} \mathrm{C}$ for the $\mathrm{P}-\mathrm{OH}$ dehydration condensation process, which is consistent with that of $\alpha$-ZrP. The differences of TGA curves of $\alpha$-ZrP-I and 


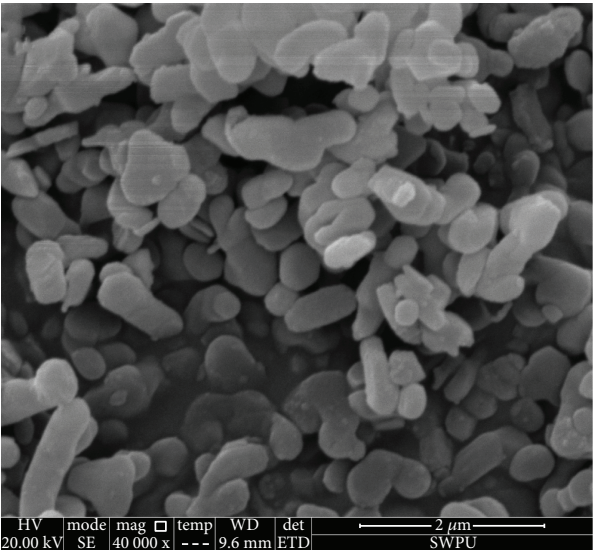

(a)

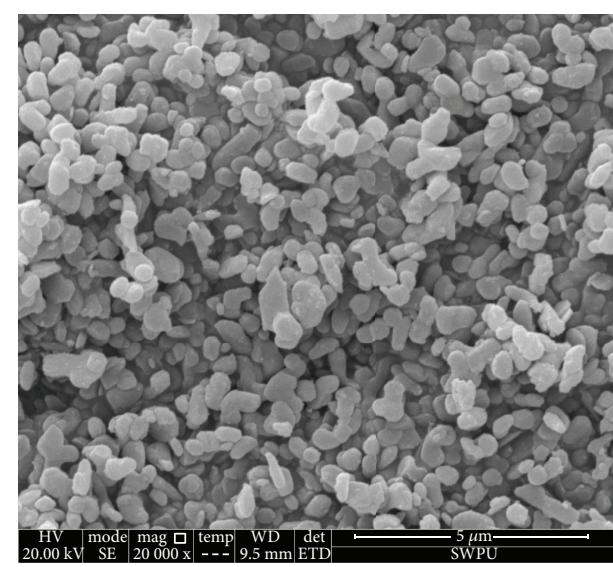

(b)

Figure 6: SEM images of $\alpha-\mathrm{ZrP}$.

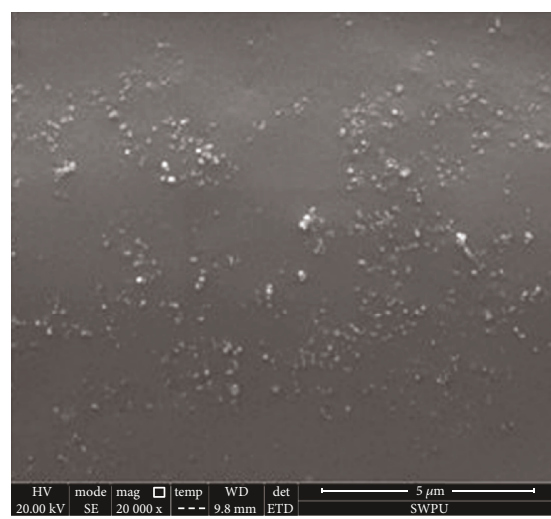

(a)

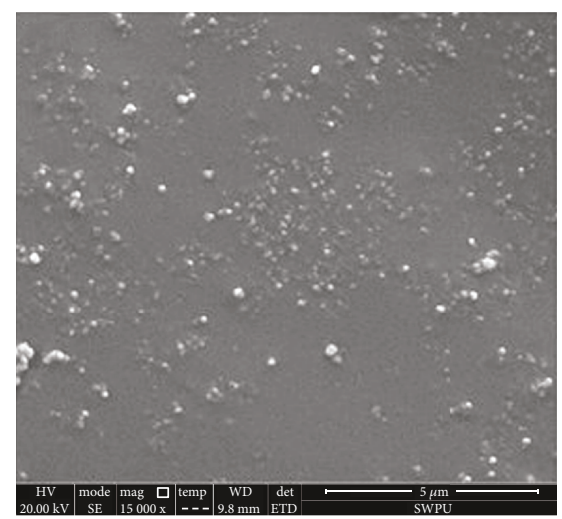

(b)

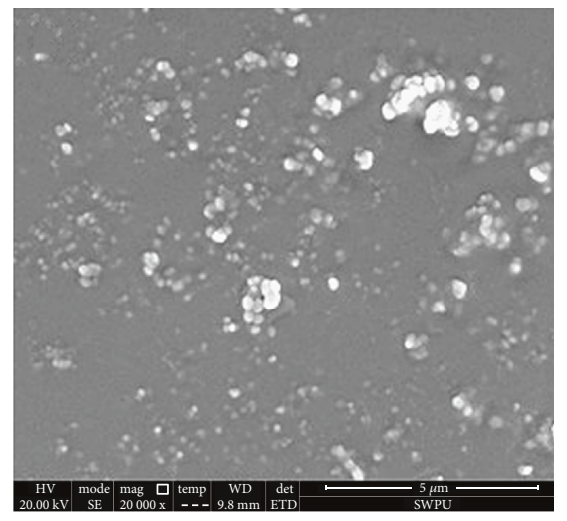

(c)

Figure 7: SEM images of $\alpha$-ZrP-I: (a) $50 \mathrm{mg} / \mathrm{l}$, (b) $100 \mathrm{mg} / \mathrm{l}$, and (c) $200 \mathrm{mg} / \mathrm{l}$.

$\alpha$ - $\mathrm{ZrP}$ indicate that octadecyl isocyanate is successfully attached to the surface or edge of the $\alpha-\mathrm{ZrP}$.

3.4. Scanning Electron Microcopy (SEM). The SEM test can visually reflect the morphology and the dispersion state of the particles in the dispersant. SEM images of the powder of $\alpha$-ZrP and $\alpha$-ZrP-I are also obtained and shown in Figure 6. It can be seen that the particle size of $\alpha-\mathrm{ZrP}$ is about $100 \sim 400 \mathrm{~nm}$.

When the hydrophobic nanomaterial $\alpha$-ZrP-I is dispersed in tetrahydrofuran, SEM images are obtained and shown in Figure 7 after dispersion system being freeze- 


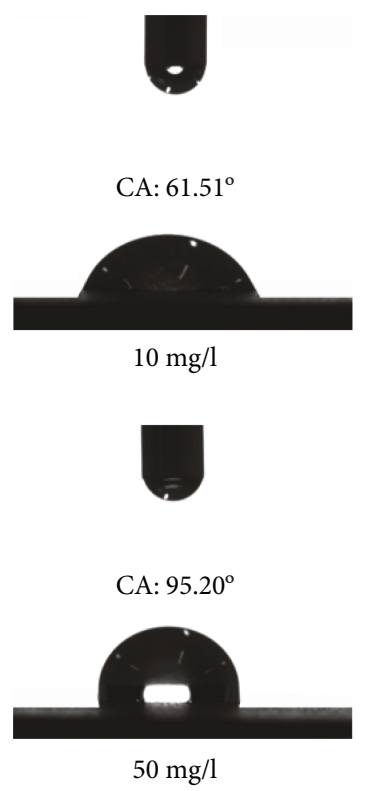

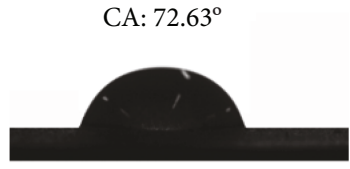

$20 \mathrm{mg} / 1$

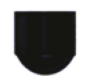

CA: $106.93^{\circ}$

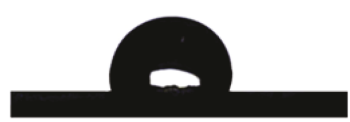

$100 \mathrm{mg} / \mathrm{l}$

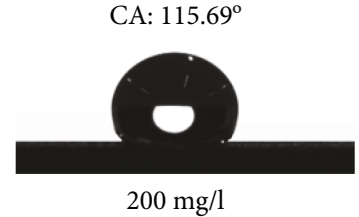

Figure 8: Contact angle on the surface of the core.

dried with liquid nitrogen and then gold sputtered. From Figure 7, it can be seen that the agglomeration of hydrophobic $\alpha$-ZrP-I increases when the concentration of $\alpha$-ZrP-I increases. Figure 7 (a) shows that the $\alpha$-ZrP-I nanoparticles could be well dispersed in tetrahydrofuran, and the particle size is less than $100 \mathrm{~nm}$. Figure 7 (c) shows a significant aggregation phenomenon when the concentration of $\alpha-\mathrm{ZrP}-\mathrm{I}$ nanoparticle dispersion system is $200 \mathrm{mg} / \mathrm{l}$.

3.5. Evaluation of Wettability of Nanomaterial. The wettability of the nanometer material of $\alpha$-ZrP-I is evaluated, and the results are shown in Figure 8. The surfaces of the hydrophilic core slices are polished with sandpaper and then soaked in tetrahydrofuran dispersion systems of $\alpha$-ZrP-I with the concentrations of $10 \mathrm{mg} / \mathrm{l}, 20 \mathrm{mg} / \mathrm{l}, 50 \mathrm{mg} / \mathrm{l}, 100 \mathrm{mg} / \mathrm{l}$, and $200 \mathrm{mg} / \mathrm{l}$, respectively. The dispersion is then heated and volatilized, depositing $\alpha$-ZrP-I on the slice of the core. The core slice which has not been processed by $\alpha$-ZrP-I nanomaterial exhibited strong hydrophilicity. The water droplet spreads rapidly as soon as it contacts the surface of the core due to the capillarity phenomenon. The contact angle of the core with water can be considered as $0^{\circ}$. When soaked in the $\alpha$-ZrP-I dispersion systems at the concentration of $10 \mathrm{mg} / \mathrm{l}$ and $20 \mathrm{mg} / \mathrm{l}$, respectively, the contact angles of the core slices with water are less than $90^{\circ}$. When soaked in the dispersion systems at concentration higher than $50 \mathrm{mg} / \mathrm{l}$, the contact angles of the core slices with water are greater than $90^{\circ}$. With the increase of concentration of the $\alpha$-ZrP-I nanomaterial, the core surface is covered by more nanomaterial molecules, so the water droplet will contact with more hydrophobic groups and appear in the shape of a ball under the energy minimization and gravity, which accounts for the phenomenon that the wettability of the core surface changes from hydrophilic into hydrophobic.

3.6. Evaluation of Core Flooding Experiment. The ability of decompression and augmented injection of nanoparticle dispersion system with different concentrations are evaluated by the self-made low-permeability core. The experimental parameters are shown in Table 1. The experiment is carried out at $30^{\circ} \mathrm{C}$. The pressure $P_{1}$ and $P_{2}$ before and after the injection of $\alpha$-ZrP-I nanometer material dispersion system are recorded, and the water-phase permeability $K_{1}$ and $K_{2}$ are calculated according to the Darcy formula, which are shown in Table 2 and Figure 9.

From Figure 9, it can be seen that the injection pressure after $\alpha$-ZrP-I injection decreases at first and then increases with the increase of the concentration of $\alpha$-ZrP-I. When the injected concentration of $\alpha$-ZrP-I is low, the surface of the rock could not be able to form an effective adsorption layer. 
TABle 1: Parameters of the cores and experiment.

\begin{tabular}{|c|c|c|c|c|c|c|c|c|}
\hline Number & Size $(\mathrm{cm})$ & $\begin{array}{l}\text { Pore volume } \\
(\mathrm{ml})\end{array}$ & $\begin{array}{c}\text { Porosity } \\
(\%)\end{array}$ & $\begin{array}{l}\text { Permeability } \\
\left(\times 10^{-3} \mu \mathrm{m}^{2}\right)\end{array}$ & $\begin{array}{c}\text { Injection rate } \\
(\mathrm{ml} / \mathrm{min})\end{array}$ & $\begin{array}{c}\text { Concentration } \\
(\mathrm{mg} / \mathrm{l})\end{array}$ & $\begin{array}{l}\text { Injection pore } \\
\text { volume }(\mathrm{PV})\end{array}$ & $\begin{array}{c}\text { Time } \\
\text { (h) }\end{array}$ \\
\hline 1 & \multirow{4}{*}{$\Phi 2.5 \times 6.4$} & 6.2 & 19.7 & 22.3 & \multirow{4}{*}{0.5} & 20 & \multirow{4}{*}{2} & \multirow{4}{*}{24} \\
\hline 2 & & 6.3 & 20.0 & 16.7 & & 50 & & \\
\hline 3 & & 6.0 & 19.1 & 21.4 & & 100 & & \\
\hline 4 & & 6.1 & 19.4 & 15.5 & & 200 & & \\
\hline
\end{tabular}

TABLE 2: Pressure and permeability before and after $\alpha$-ZrP-I injection.

\begin{tabular}{lccccccc}
\hline Number & Concentration $(\mathrm{mg} / \mathrm{l})$ & $P_{1}(\mathrm{MPa})$ & $P_{2}(\mathrm{MPa})$ & $K_{1}\left(\times 10^{-3} \mu \mathrm{m}^{2}\right)$ & $K_{2}\left(\times 10^{-3} \mu \mathrm{m}^{2}\right)$ & Pressure drop rate $(\%)$ & $K_{2} / K_{1}$ \\
\hline 1 & 20 & 0.3527 & 0.3348 & 3.08 & 3.25 & 0.05 & 1.05 \\
2 & 50 & 0.3614 & 0.1907 & 3.01 & 5.70 & 47.23 \\
3 & 100 & 0.3703 & 0.4006 & 2.93 & 2.71 & -8.18 \\
4 & 200 & 0.2815 & 0.5024 & 3.86 & 2.16 & 0.92 \\
\hline
\end{tabular}

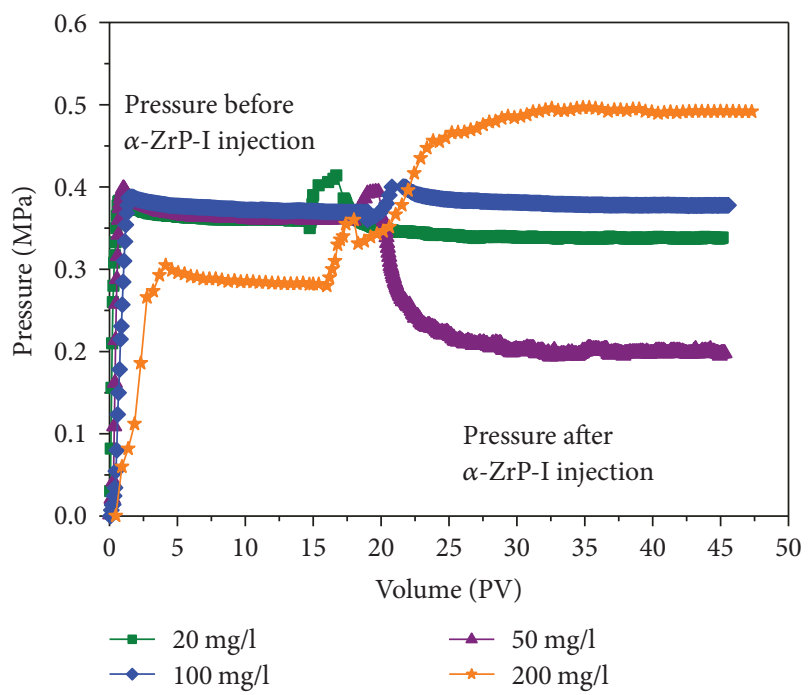

Figure 9: Pressure before and after $\alpha$-ZrP-I injection.

Therefore, nanoslip impact is not obvious and the injection pressure has a little change. As the concentration of $\alpha-\mathrm{ZrP}-\mathrm{I}$ increases to $50 \mathrm{mg} / \mathrm{l}$, the pressure drop rate is up to $47.23 \%$ and water permeability increased to 1.89 times. The flow resistance is lowered through the slippage effect, which will play an important role in reducing the injection pressure. However, when the concentration of $\alpha$-ZrP-I nano dispersion system exceeds a certain value, the nanoparticles will aggregate on the surface of the rock, which will not contribute to the decompression and augmented injection effect and will increase the injection pressure. When the concentration of $\alpha-\mathrm{ZrP}-\mathrm{I}$ is more than $100 \mathrm{mg} / \mathrm{l}$, the depressurization effect disappears. The results of the experiments in this paper show that $50 \mathrm{mg} / \mathrm{l}$ is the best concentration for $\alpha$-ZrP-I in decompression and augmented injection. Therefore, the concentration of $\alpha$-ZrP-I is crucial for decompression and augmented injection effect, which should be controlled within the appropriate range.

\section{Conclusion}

In this paper, $\alpha$-ZrP was prepared by the reflux method and then was modified by octadecyl isocyanate to prepare hydrophobically modified $\alpha$-ZrP. FTIR, XRD, and TGA measurements were utilized, and the results indicated that the octadecyl isocyanate molecules were successfully attached to the $\alpha-\mathrm{ZrP}$ crystal surface. SEM images show the morphology and the dispersion states of $\alpha$-ZrP-I particles in the dispersant. The $\alpha$-ZrP-I could be well dispersed at lower concentration, while the increase of concentration would result in the agglomeration phenomenon. The results of contact angle measurements demonstrate that the higher the concentration of $\alpha$-ZrP-I, the greater the contact angle, and the stronger the hydrophobicity of the core slice. The results of water flooding experiments indicate that appropriate concentration of $\alpha$-ZrP-I has positive effect on decompression and augmented injection. The results of this paper may lay a firm foundation for further industrial applications of $\alpha-\mathrm{ZrP}$ and its derivatives in oilfield exploitation.

\section{Conflicts of Interest}

The authors declare that they have no conflicts of interest.

\section{Acknowledgments}

This work was supported by the National Natural Science Foundation of China (Grant no. 51674210).

\section{References}

[1] M. Tang, T. S. Yang, and Y. Zhang, "A brief review on $\alpha$-zirconium phosphate intercalation compounds and nano- 
composites," Science China Technological Sciences, vol. 59, no. 3, pp. 436-441, 2016.

[2] W. Liu, H. Wang, M. He, J. Zhong, and R. Chen, "Factors affect on the synthesis of silica-pillared zirconium phosphate with template-directing self-assembly method and its epoxidation catalytic performance," Catalysis Letters, vol. 144, no. 4, pp. 663-673, 2014.

[3] Y. Du, F. Deng, X. Jiang et al., "Preparation and performance of lipophilic $\alpha$-zirconium phosphate with high thermal stability and its application in thermal-plastic polymers," Progress in Natural Science: Materials International, vol. 25, no. 5, pp. 503-511, 2015.

[4] A. Pattammattel, I. K. Deshapriya, R. Chowdhury, and C. V. Kumar, "Metal-enzyme frameworks: role of metal ions in promoting enzyme self-assembly on $\alpha$-zirconium(IV) phosphate nanoplates," Langmuir, vol. 29, no. 9, pp. 2971-2981, 2013.

[5] V. Saxena, A. Diaz, A. Clearfield, J. D. Batteas, and M. D. Hussain, "Zirconium phosphate nanoplatelets: a biocompatible nanomaterial for drug delivery to cancer," Nanoscale, vol. 5, no. 6, pp. 2328-2336, 2013.

[6] A. Díaz, A. David, R. Pérez et al., "Nanoencapsulation of insulin into zirconium phosphate for oral delivery applications," Biomacromolecules, vol. 11, no. 9, pp. 2465-2470, 2010.

[7] R. Silbernagel, C. H. Martin, and A. Clearfield, "Zirconium (IV) phosphonate-phosphates as efficient ion-exchange materials," Inorganic Chemistry, vol. 55, no. 4, pp. 1651-1656, 2016.

[8] A. A. Martí and J. L. Colón, "Photophysical characterization of the interactions among tris $\left(2,2^{\prime}\right.$-bipyridyl) ruthenium (II) complexes ion-exchanged within zirconium phosphate," Inorganic Chemistry, vol. 49, no. 16, pp. 7298-7303, 2010.

[9] X. He, H. Xiao, H. Choi et al., " $\alpha$-Zirconium phosphate nanoplatelets as lubricant additives," Colloids and Surfaces A: Physicochemical and Engineering Aspects, vol. 452, pp. 32-38, 2014.

[10] Z. D. Cheng, M. Shuai, A. Mejia et al., "Disk-shaped colloids: the synthesis and applications of ZrP crystals," Advanced Materials Research, vol. 787, pp. 177-183, 2013.

[11] T. Takei, Y. Kobayashi, H. Hata et al., "Anodic electrodeposition of highly oriented zirconium phosphate and polyanilineintercalated zirconium phosphate films," Journal of the American Chemical Society, vol. 128, no. 51, pp. 1663416640, 2006.

[12] W. Boo, L. Sun, J. Liu et al., "Morphology and mechanical behavior of exfoliated epoxy/ $\alpha$-zirconium phosphate nanocomposites," Composites Science and Technology, vol. 67, no. 2, pp. 262-269, 2007.

[13] B. Ha, K. Char, and H. S. Jeon, "Intercalation mechanism and interlayer structure of hexadecylamines in the confined space of layered alpha-zirconium phosphates," The Journal of Physical Chemistry B, vol. 109, no. 51, pp. 24434-24440, 2005.

[14] B. M. Mosby, M. Goloby, A. Díaz, V. Bakhmutov, and A. Clearfield, "Designable architectures on nanoparticle surfaces: zirconium phosphate nanoplatelets as a platform for tetravalent metal and phosphonic acid assemblies," Langmuir, vol. 30, no. 9, pp. 2513-2521, 2014.

[15] A. Díaz, B. M. Mosby, V. I. Bakhmutov, A. A. Martí, J. D. Batteas, and A. Clearfield, "Self-assembled monolayers based upon a zirconium phosphate platform," Chemistry of Materials, vol. 25, no. 5, pp. 723-728, 2013.

[16] A. Díaz, V. Saxena, J. González et al., "Zirconium phosphate nano-platelets: a novel platform for drug delivery in cancer therapy," Chemical Communications, vol. 48, no. 12, pp. 1754-1756, 2012.

[17] M. Pica, A. Donnadio, D. Capitani, R. Vivani, E. Troni, and M. Casciola, "Advances in the chemistry of nanosized zirconium phosphates: a new mild and quick route to the synthesis of nanocrystals," Inorganic Chemistry, vol. 50, no. 22, pp. 11623-11630, 2011.

[18] D. Capitani, M. Casciola, A. Donnadio, and R. Vivani, "High yield precipitation of crystalline $\alpha$-zirconium phosphate from oxalic acid solutions," Inorganic Chemistry, vol. 49, no. 20, pp. 9409-9415, 2010.

[19] L. Sun, W. J. Boo, H.-J. Sue, and A. Clearfield, "Preparation of $\alpha$-zirconium phosphate nanoplatelets with wide variations in aspect ratios," New Journal of Chemistry, vol. 31, no. 1, pp. 39-43, 2007.

[20] M. Shuai, A. F. Mejia, Y.-W. Chang, and Z. Cheng, "Hydrothermal synthesis of layered $\alpha$-zirconium phosphate disks: control of aspect ratio and polydispersity for nano-architecture," CrystEngComm, vol. 15, no. 10, 2013.

[21] X. Q. Liu, D. Y. Wang, X. L. Wang, L. Chen, and Y. Z. Wang, "Synthesis of functionalized $\alpha$-zirconium phosphate modified with intumescent flame retardant and its application in poly(lactic acid)," Polymer Degradation and Stability, vol. 98, no. 9, pp. 1731-1737, 2013.

[22] H. Wu, C. Liu, J. Chen, Y. Yang, and Y. Chen, "Preparation and characterization of chitosan $\alpha$-zirconium phosphate nanocomposite films," Polymer International, vol. 59, no. 7, pp. 923-930, 2010.

[23] H. Wu, C. Liu, J. Chen, P. R. Chang, Y. Chen, and D. P. Anderson, "Structure and properties of starch $/ \alpha$-zirconium phosphate nanocomposite films," Carbohydrate Polymers, vol. 77, no. 2, pp. 358-364, 2009.

[24] L. Sun, W. J. Boo, D. Sun, A. Clearfield, and H.-J. Sue, "Preparation of exfoliated epoxy $/ \alpha$-zirconium phosphate nanocomposites containing high aspect ratio nanoplatelets," Chemistry of Materials, vol. 19, no. 7, pp. 1749-1754, 2007.

[25] Y. Cheng, X. T. Wang, S. Jaenicke, and G. K. Chuah, "Minimalistic liquid-assisted route to highly crystalline $\alpha$-zirconium phosphate," ChemSusChem, vol. 10, no. 16, pp. 3235-3242, 2017.

[26] A. Clearfield, J. D. Wang, Y. Tian, E. Stein, and C. Bhardwaj, "Synthesis and stability of mixed ligand zirconium phosphonate layered compounds," Journal of Solid State Chemistry, vol. 117, no. 2, pp. 275-289, 1995.

[27] J. S. Xu, Y. Tang, H. Zhang, and Z. Gao, "Studies on colloidization and stability of layered phosphates in amine hydrous solution," Chemical Journal of Chinese Universities, vol. 18, no. 1, pp. 93-98, 1997.

[28] R. Zhang, Y. Hu, B. Li, Z. Chen, and W. Fan, "Studies on the preparation and structure of polyacrylamide/ $\alpha$-zirconium phosphate nanocomposites," Journal of Materials Science, vol. 42, no. 14, pp. 5641-5646, 2007.

[29] M. Casciola, D. Capitani, A. Donnadio, G. Munari, and M. Pica, "Organically modified zirconium phosphate by reaction with 1,2-epoxydodecane as host material for polymer intercalation: synthesis and physicochemical characterization," Inorganic Chemistry, vol. 49, no. 7, pp. 3329-3336, 2010.

[30] B. M. Mosby, A. Díaz, and A. Clearfield, "Surface modification of layered zirconium phosphates: a novel pathway to multifunctional materials," Dalton Transactions, vol. 43, no. 27, pp. 10328-10339, 2014. 
[31] S. K. Shi, R. L. Zong, Y. Liu, Y. H. Wang, and J. Zhou, "Characteristics of surfactant-zirconium phosphate composites with expanded interlayer separation," Key Engineering Materials, vol. 336-338, pp. 2589-2591, 2007.

[32] D. J. MacLachlan and K. R. Morgan, "Phosphorus-31 solidstate NMR studies of the structure of amine-intercalated .alpha.-zirconium phosphate: reaction of .alpha.-zirconium phosphate with excess amine," The Journal of Physical Chemistry, vol. 94, no. 19, pp. 7656-7661, 1990.

[33] J. S. Guevara, A. F. Mejia, M. Shuai, Y.-W. Chang, M. S. Mannan, and Z. Cheng, "Stabilization of Pickering foams by high-aspect-ratio nano-sheets," Soft Matter, vol. 9, no. 4, pp. 1327-1336, 2013.

[34] A. F. Mejia, A. Diaz, S. Pullela et al., "Pickering emulsions stabilized by amphiphilic nano-sheets," Soft Matter, vol. 8, no. 40, p. 10245, 2012.

[35] A. Karimi, Z. Fakhroueian, A. Bahramian et al., "Wettability alteration in carbonates using zirconium oxide nanofluids: EOR implications," Energy \& Fuels, vol. 26, no. 2, pp. 10281036, 2012.

[36] B. M. Mosby, A. Díaz, V. Bakhmutov, and A. Clearfield, "Surface functionalization of zirconium phosphate nanoplatelets for the design of polymer fillers," ACS Applied Materials \& Interfaces, vol. 6, no. 1, pp. 585-592, 2014. 


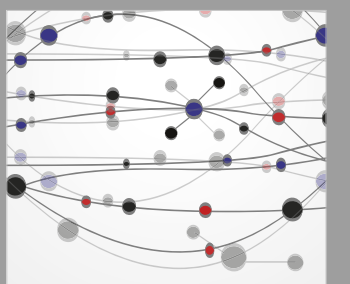

The Scientific World Journal
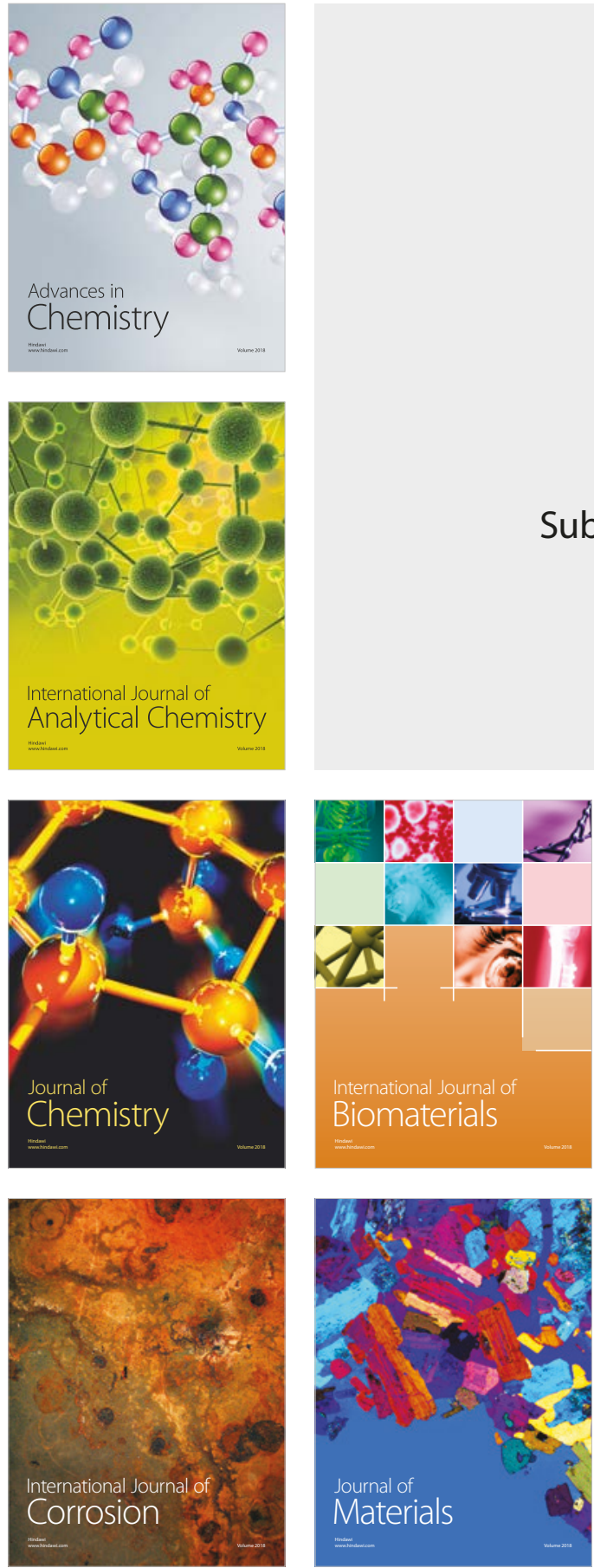

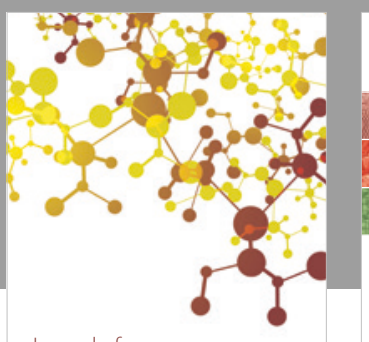

Journal of

Applied Chemistry
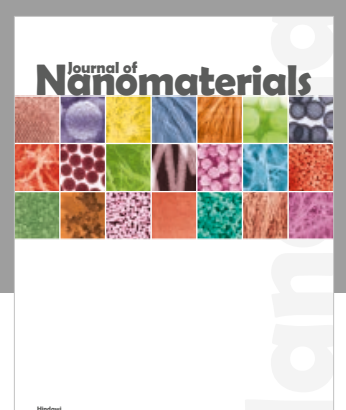

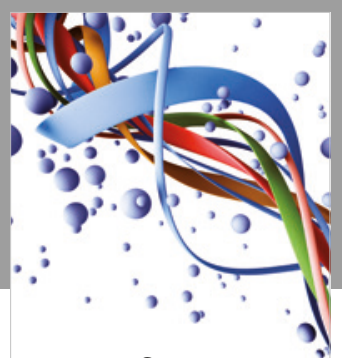

Scientifica

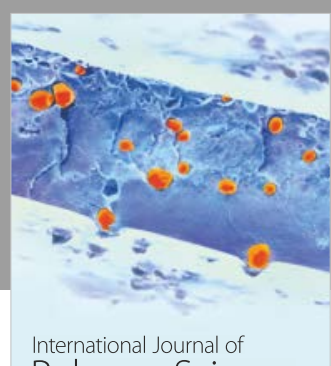

Polymer Science

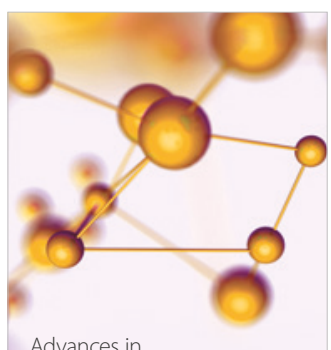

Physical Chemistry
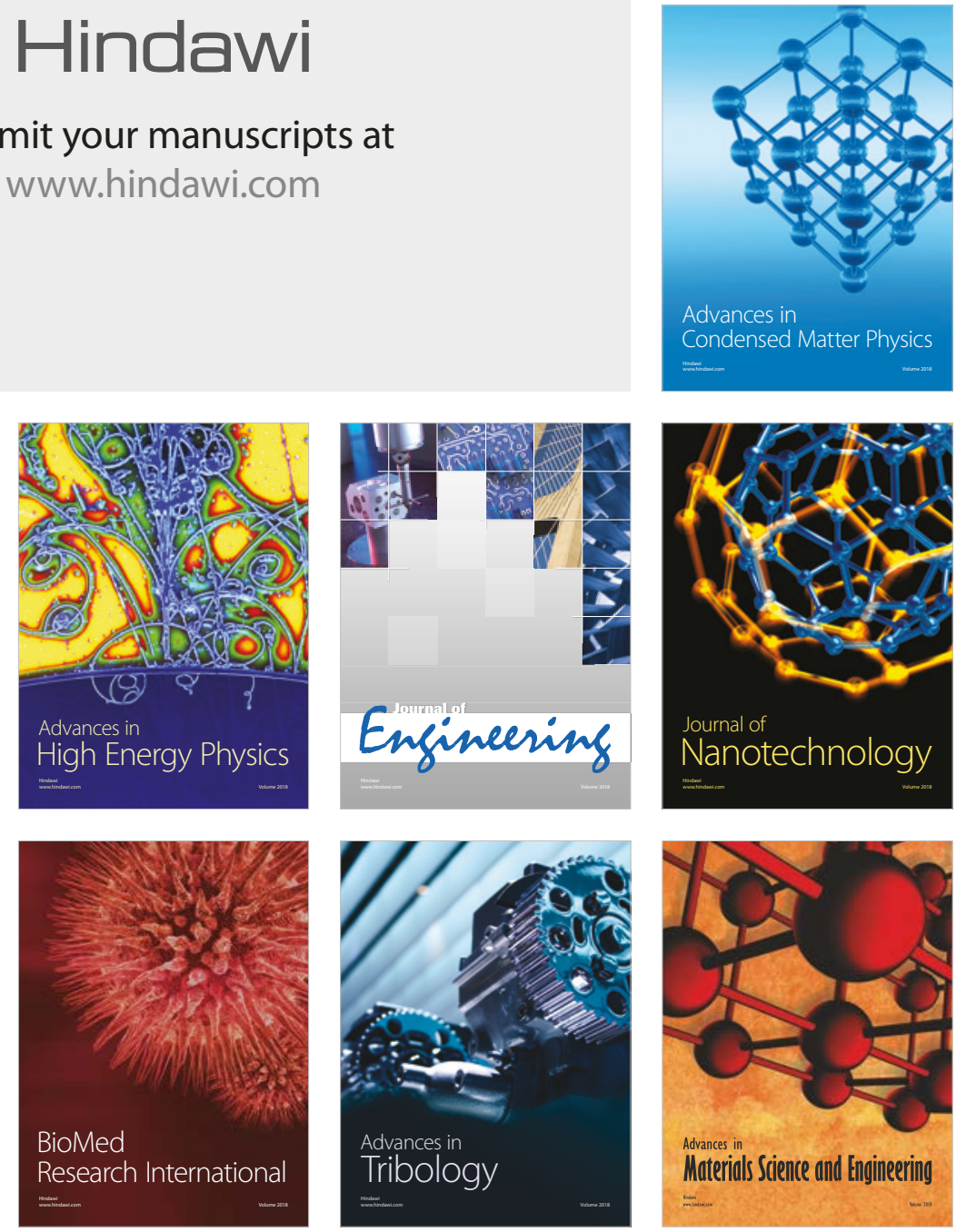